\title{
Soil Mobility of Allyl Isothiocyanate and Chloropicrin as Influenced by Surfactants and Soil Texture
}

\author{
Feras Almasri \\ Department of Plant Sciences, University of California at Davis, Davis, CA \\ 95616
}

\author{
Husein A. Ajwa \\ Department of Plant Sciences, University of California at Davis, 1636 East \\ Alisal Street, Salinas, CA 93905
}

\author{
Sanjai J. Parikh \\ University of California at Davis, Department of Land, Air and Water \\ Resources, Davis, CA 95616
}

\section{Kassim Al-Khatib ${ }^{1}$ \\ Department of Plant Sciences, University of California at Davis, Davis, CA 95616}

Additional index words. methyl bromide alternatives, allyl isothiocyanate, chloropicrin, surfactant, drip fumigation, fumigant alternatives

\begin{abstract}
Methyl bromide (MeBr) was identified as a stratospheric ozone depletory; therefore, the use of MeBr was phased out in the United States in 2005. Chloropicrin (CP) and allyl isothiocyanate (AITC) are $\mathrm{MeBr}$ replacements. A mixture of $\mathrm{CP}$ and AITC is commonly applied to broaden the pest control spectrum. These two fumigants have low soil mobility; however, their efficacy could be improved if their soil mobility were enhanced. This research was conducted to study the effects of surfactants applied at $5 \%$ (v/v) for CP mobility and AITC mobility in soils. Mobility of the CP/AITC mixture applied with a nonionic surfactant comprising oleic, linoleic, and palmitic acids (nonionic-1) and mobility of the CP/AITC mixture applied with a nonionic surfactant comprising $\mathrm{C} 9$ hydrocarbon aromatics and calcium alkylarylsuphonate (nonionic-2) were compared with mobility of the CP/AITC mixture applied without surfactants in three soils (Elder sandy loam, Chualar loam, and Blanco clay loam) during a laboratory study. Nonionic-1 surfactant increased the concentration of total leachate collected for AITC by five and CP by 11 compared with CP/AITC applied alone. Surfactants may influence the fumigant mobility in soil by affecting the sorption/desorption equilibrium. Our research suggested that increased AITC mobility and CP mobility in soil with the addition of adding nonionic-1 surfactant may be due to the adsorption behavior of the surfactant in the soil and the solubilizing capability of the surfactant with pesticides.
\end{abstract}

During the past 55 years, methyl bromide $(\mathrm{MeBr})$ has been the most effective soil fumigant for controlling soil pests in California high-value crops (Johnson et al., 2012). $\mathrm{MeBr}$ is a highly effective biocide that has a consistent and broad pest control spectrum and short plant-back periods (Jacoby, 2016). $\mathrm{MeBr}$ is a gas that has a low boiling point and high vapor pressure; such properties allow $\mathrm{MeBr}$ to move through soil unimpeded, resulting in high pest control efficacy. However, in the early 1990s, MeBr was identified as a stratospheric ozone depletor (Butler and Rodriguez, 1996); therefore, the use of $\mathrm{MeBr}$ was phased out in the United States (Butler

Received for publication 20 Dec. 2018. Accepted for publication 31 Jan. 2019.

We thank Isagro USA for partially funding the study. No conflicts of interest have been declared. ${ }^{1}$ Corresponding author. E-mail: kalkhatib@ucdavis. edu. and Rodriguez, 1996; Downing, 2016; Jacoby, 2016; Johnson et al., 2012). Although $\mathrm{MeBr}$ was used on many crops, California strawberries were the most economically impacted by the phase-out, and this helped strawberry farmers win a critical use exemption that allowed small quantities of $\mathrm{MeBr}$ to be used until 2016 (Downing, 2016).

Research showed that the soil fumigants that are alternatives to $\mathrm{MeBr}$ are generally less effective pest control agents. These alternatives to $\mathrm{MeBr}$ include chloropicrin (CP), 1,3-dichloropropene (1,3-D), methyl isothiocyanate (MITC) generators such as metam sodium (Met-Na), metam potassium (Met-K), and dimethylformocarbothialdine (DMTT), and synthetic allyl isothiocyanate (AITC) (Gao et al., 2012; Klose et al., 2008). Additionally, research has shown that to obtain acceptable pest control levels, a combination of more than one fumigant must be applied. For example, 1,3-D controls nematodes and some soil arthropods, but it provides little control of fungi and weeds, whereas Met-Na controls weeds, nematodes, and some fungi. $\mathrm{CP}$ controls insects and fungi, but it has less activity against nematodes and weeds (Ajwa and Trout, 2004). The most promising $\mathrm{MeBr}$ alternatives are chloropicrin and Met-Na (Gao et al., 2012; Jacoby, 2016; Klose et al., 2008; Yates et al., 2002); therefore, more than 7000 tons of chloropicrin were used in 2011 (Nelson et al., 2013) in California.

Although Met-Na is an effective fumigant (Nelson et al., 2002), the use of Met-Na is strongly regulated due to the excessive soil fumigant release into the atmosphere (Goodhue et al., 2016; Saeed et al., 1997). Because of this excessive release into the atmosphere, Met-Na, Met-K, and DMTT labels require wide buffer zones and specific measures to protect people from off-target movement (Guthman and Brown, 2016). Furthermore, Met-Na, Met-K, and DMTT degrade in soil to MITC, which is classified as a toxicity I category pesticide (Gao et al., 2012; Klose et al., 2008)

Recently, the United States Environmental Protection Agency (EPA) approved the registration of synthetic AITC as a preplant soil bio-fumigant (Isagro, 2016). AITC is a natural product produced by Brassica plants to defend against insects and diseases (Ahuja et al., 2010). Brassica plants naturally produce glucosinolate, which is converted to AITC by the enzyme myrosinase when plants are attacked or mechanically damaged. Several reports showed that AITC performed as well as $\mathrm{MeBr}$ and Met-Na when applied as a preplant soil treatment (Bangarwa et al., 2011; Devkota and Norsworthy, 2014). Moreover, research showed that AITC is effective for controlling select weeds (Bangarwa et al., 2011; Devkota and Norsworthy, 2014), nematodes (Wu et al., 2011), insects (Noble et al., 2002), and plant soil pathogens (Gilardi et al., 2000).

Synthetic AITC is not considered a restricted use pesticide; therefore, it differs from all other fumigant alternatives. AITC can be applied to all crops during the preplant period, has a maximum buffer zone of $7.5 \mathrm{~m}$, has no limit regarding the number of hectares that can be treated per day, and has no restrictions regarding the type of covering film used with it (Isagro, 2016). AITC is considered generally regarded as safe (GRAS) by the Food and Drug Administration, and it is a food additive approved for direct human consumption as a synthetic flavoring substance and adjuvant (FDA, 2018).

It is difficult to find a chemical with biological, chemical, and physical properties similar to those of $\mathrm{MeBr}$ that will pass regulations and that is relatively easy to transport and apply. MeBr has a boiling point of $4.5^{\circ} \mathrm{C}$ and a vapor pressure of $218.6 \mathrm{kPa}$; however, for MITC, CP, and AITC, the boiling points are 119,112 , and $150{ }^{\circ} \mathrm{C}$, respectively, and vapor pressures are 1.73, 2.44, and $0.49 \mathrm{kPa}$, respectively (Downing, 2016; Jacoby 2016; Nelson et al., 2013). The high boiling point and relatively low vapor pressure of $\mathrm{MeBr}$ alternatives do not allow these fumigants 
to exist in a gas phase in their original state. Liquid fumigants need to convert to a volatile or semi-volatile state to control soil-borne pests; therefore, the dispersal rate and the ability of a fumigant to move in soil at high concentrations will determine the effectiveness of the fumigant (Nelson et al., 2013).

In California, $\mathrm{MeBr}$ alternatives are usually applied to the soil through drip irrigation (also known as chemigation); however, in many other places, shank applications are still a common application method for fumigants. During drip irrigation, polyethylene plastic mulch is installed before the application of the fumigants, and this application method is gaining popularity with growers due to limited worker exposure (Jacoby, 2016; Nelson et al., 2013). Although Met$\mathrm{Na}$ and other isothiocyanate generators are popular and widely used as $\mathrm{MeBr}$ alternatives, previous research suggested that soil-borne pest control with Met-Na is inconsistent because application methods seldom achieve optimum distribution of Met-Na (Gilreath et al., 2008; Rodriguez-Kabana, 2002). This is especially important in sandy soils in which lateral water movement is limited (Papiernik et al., 2004; Yates et al., 2002). Met-Na principle derivative (MITC) is not very mobile in soil, and AITC has less mobility in soil than MITC (Jacoby, 2016).
Multiple reports have shown that the efficacy of isothiocyanate generators could be improved by increasing the residence time of the fumigant in soil (Nelson et al., 2013). As a result, several researchers investigated different application methods that could provide better fumigant soil distribution by physical means such as multiple drip lines, using totally impermeable film, and adjusting water application rates and volumes (Nelson et al., 2013; Papiernik et al., 2004; Yates et al., 2002). Such methods have indirectly led to improving molecular diffusion of fumigants and their persistence in soils (López-Fernández et al., 2016).

It has been reported that the efficacy of Met-Na was improved when applied with the soil surfactant Integrate (triblock co-polymer and glucoethers) (Santos et al., 2013). Furthermore, Santos et al. (2013) observed a significant reduction in the number of propagules of purple nutsedge when a soil surfactant was added to Met-K compared with Met-K applied alone. Furthermore, the use of surfactants to influence pesticide movement in soil has been reported. Sanchez-Camazano et al. (1995) described how the addition of surfactants influenced nonionic pesticide mobility in soil. Moreover, Katagi (2008) discussed how surfactants modify the environmental behavior of pesticides, and Mao et al. (2015) described

Table 1. Physical and chemical properties of three soils (Elder sandy loam, Chualar loam, and Blanco clay loam) collected from strawberry production areas in the coastal region of California. Soil samples were collected in Feb. 2016.

\begin{tabular}{lccc}
\hline Measurement & Elder sandy loam & Chualar loam & Blanco clay loam \\
\hline Saturation (\%) & 19 & 20 & 47 \\
pH & 5.78 & 6.73 & 7.13 \\
EC (dS/m) & 2.71 & 1.13 & 4.29 \\
Organic matter (\%) & 1.5 & 1.7 & 3.5 \\
CEC (mEq/100 g) & 7.4 & 12.8 & 54.8 \\
Sand \% & 70 & 66 & 30 \\
Silt \% & 22 & 28 & 64 \\
Clay \% & 8 & 6 & 6 \\
\hline
\end{tabular}

how surfactants can be used to remediate soils by influencing the solubility of pesticide residue in soil. However, all reports agree that the ability to enhance fumigant efficacy with surfactants depends on the type of surfactant (anionic, nonionic, or cationic) used and soil properties because soil surfactant generally alters the bonding properties of soil-water interactions. Although the effects of soil surfactants on the pest control efficacy of Met-Na have been well-studied, questions remain regarding whether the type of surfactant affects the pest control efficacy of other fumigants such as AITC and CP. Therefore, the objective of this study was to characterize and quantify the effects of different surfactants on AITC mobility and CP mobility and their distributions in different soils.

\section{Materials and Methods}

Soil preparation. Soils were collected from strawberry fields in Watsonville and Salinas in the coastal area of California, which is a strawberry-growing region that comprises different soil types. The Watsonville soil was collected from the California Strawberry Commission Research facilities near Watsonville (long. $121^{\circ} 50^{\prime} \mathrm{W}$, lat. $36^{\circ} 54^{\prime} \mathrm{N}$ ). The Watsonville soil was classified as an Elder sandy loam (coarse-loamy, mixed, thermic, Cumulic Haploxeroll). The other two soils were collected from the United States Department of Agriculture (USDA) Spence research farm near Salinas (lat. 36 $37^{\prime} 36.8^{\prime \prime} \mathrm{N}$, long. $\left.21^{\circ} 32^{\prime} 11.6^{\prime \prime} \mathrm{W}\right)$ and from a commercial field located on Davis Road (Blanco district) near Salinas (lat. $36^{\circ} 40^{\prime} 48.3^{\prime \prime} \mathrm{N}$, long. $\left.121^{\circ} 41^{\prime} 04.7^{\prime \prime} \mathrm{W}\right)$. The Spence soil is classified as Chualar loam (fine-loamy, mixed, thermic Typic Argixerolls), whereas the Davis Road soil is classified as Blanco clay loam (fineloamy, mixed, superactive, thermic Pachic Haploxerolls). Soils in this study are referred to by their classification name (Elder sandy

Table 2. Statistical evaluation of the pseudo first-order reaction constants (K) for the leaching of allyl isothiocyanate (AITC) and chloropicrin (CP) using different surfactants. $\mathrm{K}$ is first-order reaction rate of the different surfactants and fumigants used, t0.5 is the half-life, $\mathrm{R}$ is the correlation coefficient, and sE is the standard error.

\begin{tabular}{|c|c|c|c|c|c|}
\hline Soil type & Treatment & $\mathrm{K}\left(\mathrm{ppm} \cdot \mathrm{min}^{-1}\right)$ & $\mathrm{t}_{0.5}(\mathrm{~min})$ & $\mathrm{R}$ & SE \\
\hline Elder sandy loam & AITC+nonionic-2 & 0.1807 & 3.84 & 0.74 & 0.0509 \\
\hline \multirow{2}{*}{ Chualar loam } & AITC+nonionic-1 & 0.1124 & 6.17 & 0.94 & 0.0123 \\
\hline & AITC + nonionic-2 & 0.0176 & 39.38 & 0.96 & 0.0033 \\
\hline Blanco clay loam & AITC + nonionic-2 & 0.0055 & 126.00 & 0.90 & 0.0029 \\
\hline \multirow[t]{3}{*}{ Elder sandy loam } & $\mathrm{CP}$ & 0.1224 & 5.66 & 0.84 & 0.0273 \\
\hline & $\mathrm{CP}+$ nonionic -1 & 0.1123 & 6.17 & 0.70 & 0.0402 \\
\hline & $\mathrm{CP}+$ nonionic -2 & 0.0576 & 12.03 & 0.90 & 0.0124 \\
\hline Chualar loam & $\mathrm{CP}$ & 0.0213 & 32.54 & 0.93 & 0.0043 \\
\hline Blanco clay loam & $\mathrm{CP}+$ nonionic -2 & $3.09 \mathrm{E}^{-07}$ & $2.24 \mathrm{E}^{+06}$ & 0.94 & 0.0002 \\
\hline
\end{tabular}



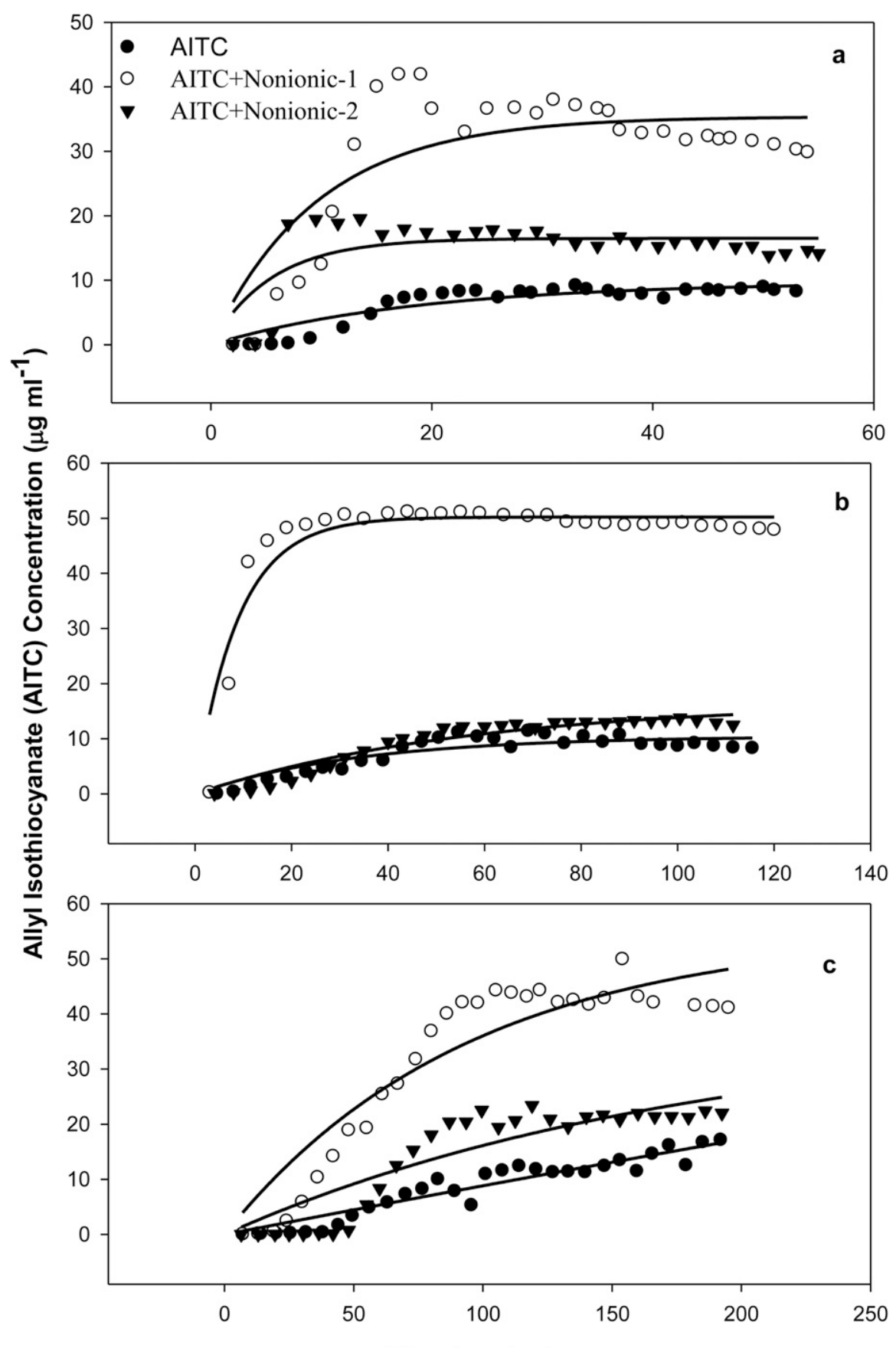

Time in minutes

Fig. 1. First-order reaction rate model fitting of allyl isothiocyanate (AITC) in leachate when applied alone, with nonionic-1, or with nonionic-2 in Elder sandy loam soil (A), Chualar loam soil (B), and Blanco clay loam soil (C). SE bars are not shown for clarity of the graph.

loam, Chualar loam, and Blanco clay loam). Soils were air-dried and then passed through a 4-mm sieve and homogenized. Soil texture (Kroetsch and Wang, 2008), soil organic matter (Cuniff, 1995), cation exchange capacity (Rible and Quick, 1960), and soil bulk density (Blake and Hartge, 1986) were determined (Table 1).

Chemicals and surfactants. Technical grade AITC (98\%; Sigma-Aldrich, St. Louis, MO) and CP (99.7\%; Sigma-Aldrich) were used in the study. A combination of AITC and CP was applied at $250 \mathrm{~kg} / \mathrm{ha}$ for each fumigant (UCIPM, 2019). The AITC/CP
USA, Morrisville, NC). This surfactant is a nonionic blend comprising oleic acid, linoleic acid, and palmitic acid. The second surfactant is a commercial nonionic surfactant from Trical Inc. (Hollister, CA) comprising hydrocarbons, C9 aromatics, and calcium alkylarylsuphonate; it is referred to here as nonionic-2. Potassium bromide was used as a tracer for fumigant mobility. Research showed that bromide is the tracer least adsorbed on soil particles (Everts et al., 1989). A 0.01-M calcium chloride solution was used for the aqueous phase in the study. The calcium chloride solution mimicked the properties of rain and irrigation water to allow a better understanding of fumigant leaching under field conditions (Ajwa and Trout, 2006). In addition, calcium aided in preventing soil dispersion.

Soil column preparation and packing. Glass columns with a $4.5-\mathrm{cm}$ inner diameter and $20-\mathrm{cm}$ length $\left(318.1 \mathrm{~cm}^{3}\right.$ volume) were used. Duplicate columns of each soil were prepared for each treatment, and each study was repeated twice. The treatments were the AITC/CP mixture applied alone or in a mixture with the anionic-1 or anionic-2 surfactant. Empty columns were weighed, and a piece of glass wool was added to the column outlet to prevent plugging. A 2- to 3$\mathrm{cm}$ layer of silica sand was added to the bottom of the column, and each column was weighed again. The sieved soil had been thoroughly mixed and was uniformly packed in the columns. Soil was added to the column and manually shaken to ensure that soil columns represented the bulk density of each soil type $\left(\approx 1.25 \mathrm{~g} \cdot \mathrm{cm}^{-3}\right.$ for the Elder sandy loam and the Chualar loam soils and 1.35 $\mathrm{g} \cdot \mathrm{cm}^{-3}$ for the Blanco clay Loam), and then each column was weighed. An additional 2 to $3 \mathrm{~cm}$ of silica sand was added to the top of the column to ensure that the surface of the soil would not be disturbed. After packing, the columns were slowly saturated from the bottom to remove entrapped air by immersing them in a container filled with aqueous $0.01 \mathrm{M} \mathrm{CaCl}_{2}$ solution. The columns were maintained in solution overnight; then, they were removed from the containers and weighed again. Tubes with a clip were then inserted at the bottom of each column to prevent drainage. Columns were placed in a rack, and each column was connected to a Mariotte apparatus containing an aqueous $0.01-\mathrm{M} \mathrm{CaCl}_{2}$ solution. The leaching solution $\left(0.01 \mathrm{M} \mathrm{CaCl}_{2}\right.$ artificial water) was added to maintain $3 \mathrm{~cm}$ of ponding water on the surface (constant water head). The amount of water applied to each column over the course of the leachate collection was threetimes the volume of the column (Ajwa and Trout, 2006).

Chemical soil injection. A total volume of $0.3 \mathrm{~mL}$ solution of AITC/CP mixture containing $189 \mathrm{mg}$ of AITC and $189 \mathrm{mg}$ of CP per column was injected by a syringe inserted into the center of the soil column at a depth of $3 \mathrm{~cm}$ from the soil surface. Concurrently, a $300-\mathrm{mg}(0.30 \mathrm{~mL}$ of $10,000 \mathrm{ppm}$ solution) bromide solution was injected in the column 


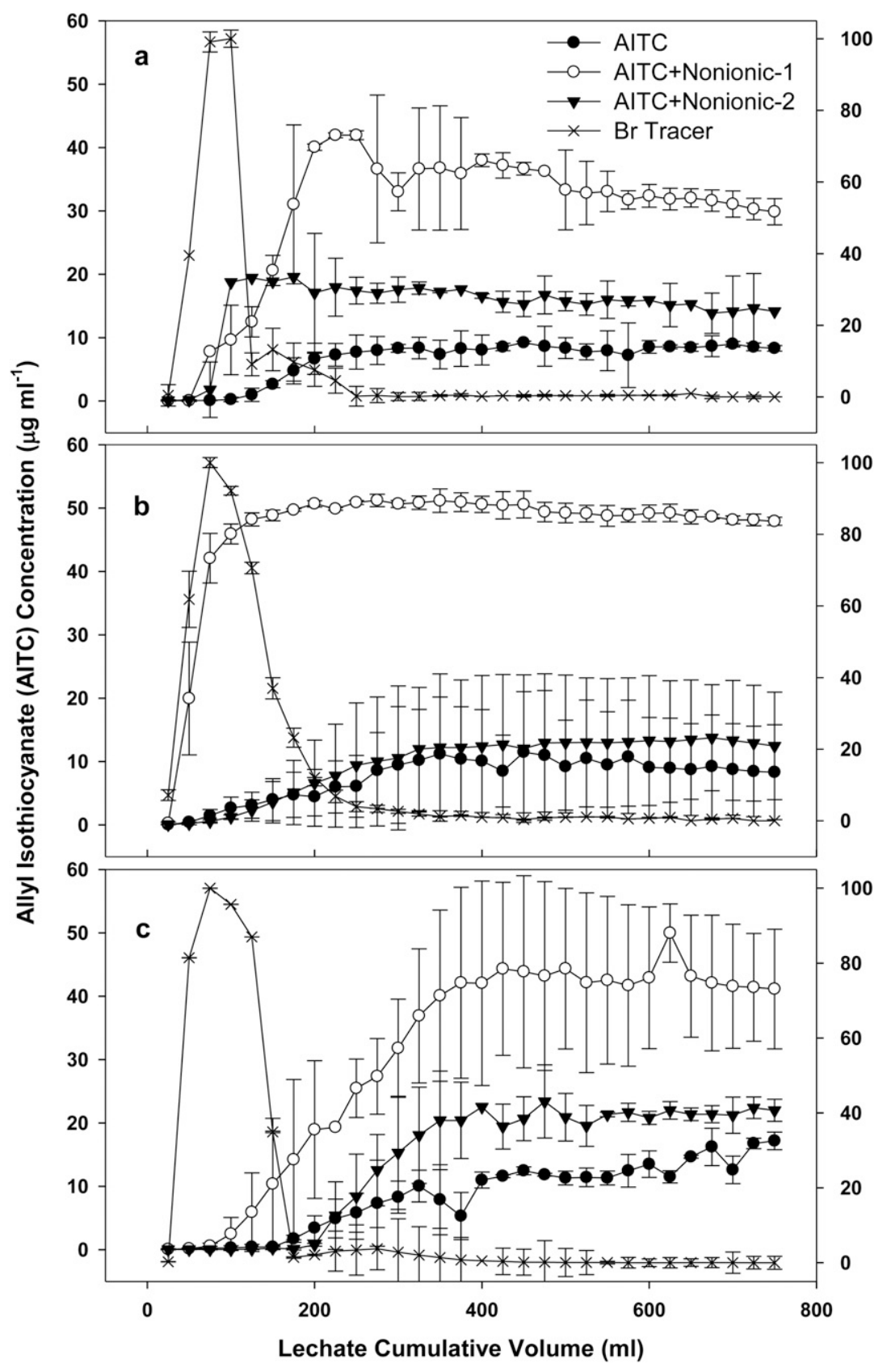

Fig. 2. Allyl isothiocyanate (AITC) and bromide tracer concentration in soil leachate collected over time from Elder sandy loam soil (A), Chualar loam soil (B), and Blanco clay loam soil (C).

at the same time and depth using a separate syringe.

AITC and CP sample collection and analysis. Immediately after AITC/CP and bromide tracer injection, the tube clip was removed to allow water to drain, and the leachate was collected by placing a $25-\mathrm{mL}$ graduated cylinder on dry ice in a beaker; this experiment was conducted at $20{ }^{\circ} \mathrm{C}$, and water used in the experiment was at $18{ }^{\circ} \mathrm{C}$. For continuous leachate collection, a second graduated cylinder was alternated to collect liquid. Thirty separate $25-\mathrm{mL}$ fractions with a total leachate volume of $750 \mathrm{~mL}$ were collected and the time for each fraction was recorded. Leachate fractions were removed from dry ice and subsampled for analysis. For each fraction, a 5-mL solution was transferred into a $20-\mathrm{mL}$ headspace vial to which $5 \mathrm{~mL}$ of ethyl acetate was added to extract the fumigants. The headspace vial was crimp-sealed and vortexed for $\approx 30 \mathrm{~s}$; then, it was frozen $\left(-10{ }^{\circ} \mathrm{C}\right)$ for later gas chromatography-mass spectrometry (GCMS) analyses.

Another 5-mL leachate sample was transferred to a Dionex cartridge, sealed, and refrigerated $\left(4{ }^{\circ} \mathrm{C}\right)$ for ion chromatography analysis. The remaining leachate was stored in a separate vial and frozen. AITC and CP concentrations were determined using the Shimadzu GCMS-QP2010 Ultra gas chromatograph with a mass-selective detector (Shimadzu Scientific Instruments, Inc., Columbia, MA) and a Zebron ZB-624 column
$(30 \mathrm{~m} \times 0.25 \mathrm{~mm} \times 1.4 \mathrm{~m}$ film thickness $)$. Bromide was quantified using ion chromatography with a Dionex DX 600 system including an LC25 chromatography oven, EG40 eluent generator, and GS50 gradient pump.

Before samples were analyzed, the analytical methods used to quantify AITC, CP, and $\mathrm{Br}^{-}$were validated using laboratoryfortified samples in soil supernatant solution. Recovery for all concurrent fortified samples were within an acceptable range $(80 \%$ to $120 \%$ ) (EPA, 1997). Performance of the analytical method was monitored by obtaining at least a 9-point calibration curve for AITC and CP and a 7-point calibration curve for $\mathrm{Br}^{-}$at the beginning and the end of each batch of samples analyzed. The calibration was checked with a standard quality control method after $\approx 15$ samples. A sample concentration that exceeded the calibration range was appropriately diluted and analyzed again such that it was within the linear response range of the standards for the injected materials. The reporting limit was set at $0.002 \mu \mathrm{g} / \mathrm{mL}$ for both AITC and CP using the Shimadzu GCMSQP2010 Ultra. Standard (quality control) and leachate-fortified (statistical process quality control) samples $(0.1 \mu \mathrm{g} / \mathrm{mL})$ of $\mathrm{AITC} / \mathrm{CP}$ were analyzed concurrently with leachate samples. The reporting limit was set at $0.094 \mu \mathrm{g} / \mathrm{mL}$ for $\mathrm{Br}^{-}$determination with the Dionex DX600 ion chromatograph. Standard quality control samples $(25 \mu \mathrm{g} / \mathrm{mL})$ of $\mathrm{Br}^{-}$were analyzed concurrently with leachate samples.

AITC and $C P$ soil residuals. After all leachates were collected, each column was wrapped in plastic cover and stored in the freezer $\left(-10{ }^{\circ} \mathrm{C}\right)$ until analysis. For soil extraction and analyses, the frozen column was removed from the freezer and divided into 3$\mathrm{cm}$ segments. The sand layer below the packed soil $(15-18 \mathrm{~cm})$ was not included in the extraction. Each segment was placed in individual storage bottles. The segments were thawed and subsamples were used to determine soil moisture content. A $10-\mathrm{g}$ soil sample was accurately weighed in a $21-\mathrm{mL}$ vial, then $1.0 \mathrm{~g}$ of sodium chloride, $5 \mathrm{~mL}$ of deionized water, and $10 \mathrm{~mL}$ of ethyl acetate were added. The vials were capped and shaken for $2 \mathrm{~h}$. Samples were allowed to settle overnight in the refrigerator $\left(4^{\circ} \mathrm{C}\right)$. Organic extract was transferred into a $12-\mathrm{mL}$ vial, and $1 \mathrm{~mL}$ of the extract was transferred into a gas chromatography vial that was capped tightly and analyzed by GCMS as described previously.

Experimental design and data analysis. Each experiment was conducted as a completely randomized design with two replications; in addition, each experiment was sequentially repeated twice. For AITC and $\mathrm{CP}$, the concentration of the extracted samples was calculated using a linear regression model obtained by plotting the peak area ( $\mathrm{y}$ axis) vs. concentration (x-axis). To obtain a better understanding of the effects of the two surfactants on AITC and CP movement in soil, leaching kinetics were determined based on a first-order reaction model that was used to calculate the pseudo first-order reaction rate constants $(\mathrm{K})$ for the leaching of AITC 
and $\mathrm{CP}$ with the two different surfactants used. Model fitting and regression analyses were performed using Sigma Plot 10.0

(Systat Software, Point Richmond, CA). The total amounts of CP and AITC in the $750-\mathrm{mL}$ volume of leachate collected were
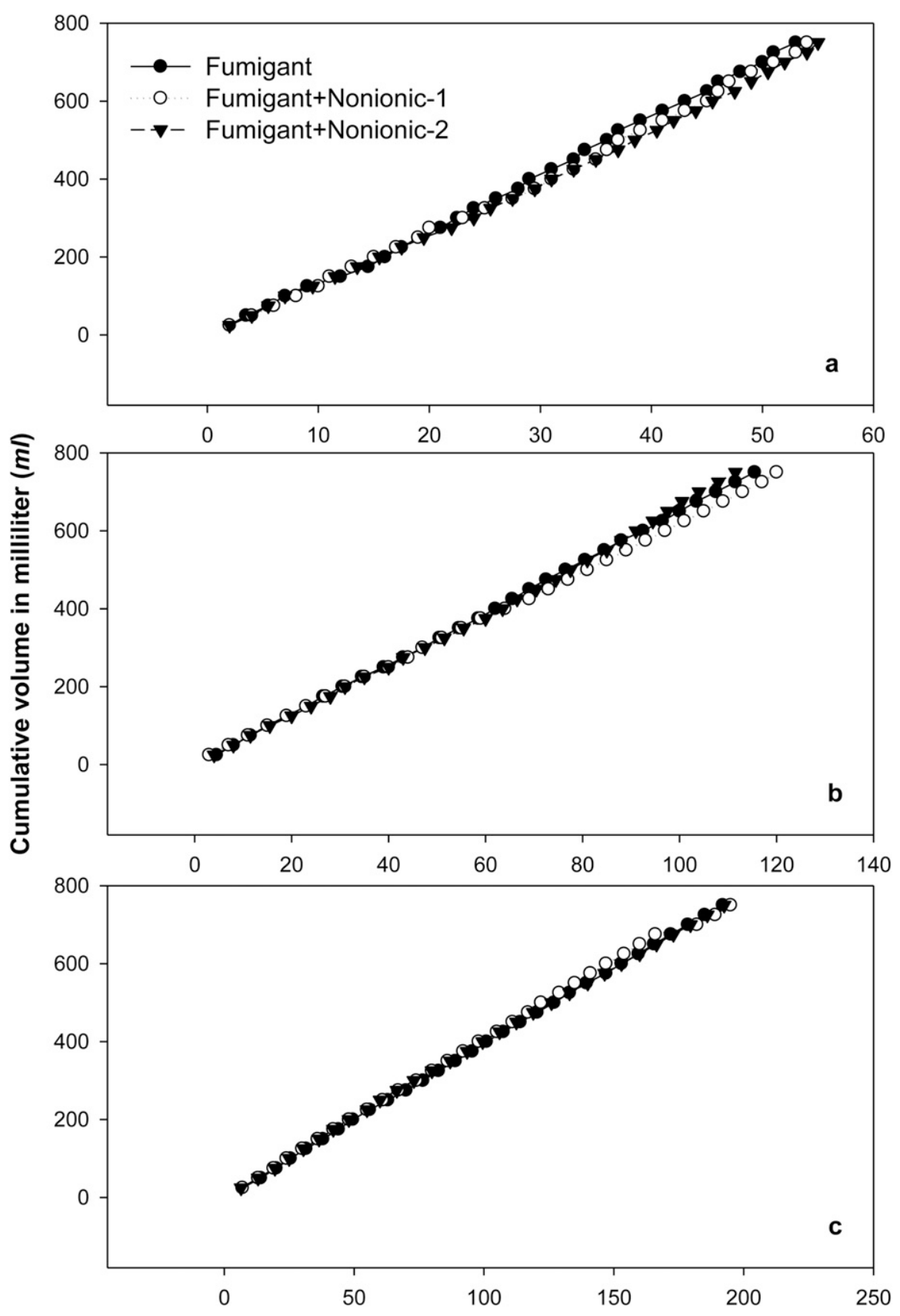

Time in Minutes ( $\mathbf{m i n})$

Fig. 3. Average time in minutes required to collect leachate fractions from Elder sandy loam soil (A), Chualar loam soil (B), and Blanco clay loam soil (C). Fumigant was applied alone or in combination with nonionic-1 surfactant or nonionic-2 surfactant. SE bars are not shown for clarity of the graph. calculated as the sum of the amount in each fraction multiplied by the fraction volume. The SE was calculated for all treatments. All data were plotted using Sigma Plot 10.0 (Systat Software).

\section{Results and Discussion}

Reaction model. Time-dependent behavior of the fumigant due to the addition of the surfactant was determined using a first-order kinetic model. The model described the linear movement of the fumigant based on concentration (Szajdak et al., 2014). The model was described by the following firstorder differential equation:

$$
-\frac{d(A)}{(A)}=K(A)
$$

Eq. [1] can be arranged as the following equation:

$$
\ln (A)=\ln (A 0)-K t
$$

$\mathrm{K}$ is the first-order rate constant in units of $\mathrm{L} /$ time, and the reaction rate unit is presented as concentration/time. The units can vary with other order reactions (Szajdak et al., 2014) Table 2 shows the statistical parameters of the first-order kinetics model with a good fit for the measured concentration change over time (Fig. 1). The actual concentrations of AITC and CP in different soils with and without the addition of a surfactant were characterized by the following exponential equation:

$$
\left(C_{t}\right)=\left(C_{\max }\right)\left(1-e^{-K t}\right)
$$

$C_{t}$ is the fumigant concentration, $C_{\max }$ is the fumigant maximum concentration, $t$ is the reaction time, and $e$ is the base of the natural logarithm. The half-life times of the fumigants were calculated using the following equation:

$$
t_{0.5}=K^{-1} \ln 2
$$

Calculation of the constant for the firstorder reaction $(\mathrm{K})$ was determined by means of the least square formula as the slope of the following equation:

$$
\ln \left(C_{\max }-C_{t}\right)=-K t
$$

The slope of Eq. [5] describes the changes in concentrations of fumigants over time. Calculated $\mathrm{R}$ values ranged between 0.74 to 0.96 for AITC and 0.70 to 0.97 for $\mathrm{CP}$ (Table 2).

AITC mobility. Without surfactant, AITC

\begin{tabular}{|c|c|c|c|c|c|c|}
\hline \multirow[b]{3}{*}{ Soil } & \multicolumn{3}{|c|}{ AITC } & \multicolumn{3}{|c|}{$\mathrm{CP}$} \\
\hline & None & Nonionic-1 & Nonionic-2 & None & Nonionic-1 & Nonionic-2 \\
\hline & \multicolumn{6}{|c|}{ - - } \\
\hline Elder sandy loam & $2.60 \pm 0.45$ & $11.69 \pm 1.33$ & $5.90 \pm 0.64$ & $2.87 \pm 0.44$ & $11.04 \pm 1.25$ & $3.66 \pm 0.82$ \\
\hline Blanco clay loam & $3.34 \pm 0.38$ & $12.21 \pm 1.25$ & $5.60 \pm 0.65$ & $1.20 \pm 0.20$ & $19.29 \pm 1.25$ & $2.47 \pm 0.50$ \\
\hline
\end{tabular}
mobility was similar across all soil classes

Table 3. Average percent recovered of applied allyl isothiocyanate (AITC) and chloropicrin (CP) in leachate in three soils affected by surfactant. Nonionic-1 (a nonionic blend comprising oleic acid, linoleic acid, and palmitic acid) and nonionic-2 (a nonionic surfactant comprising hydrocarbons, $\mathrm{C} 9$ aromatics, and calcium alkylarylsuphonate). 


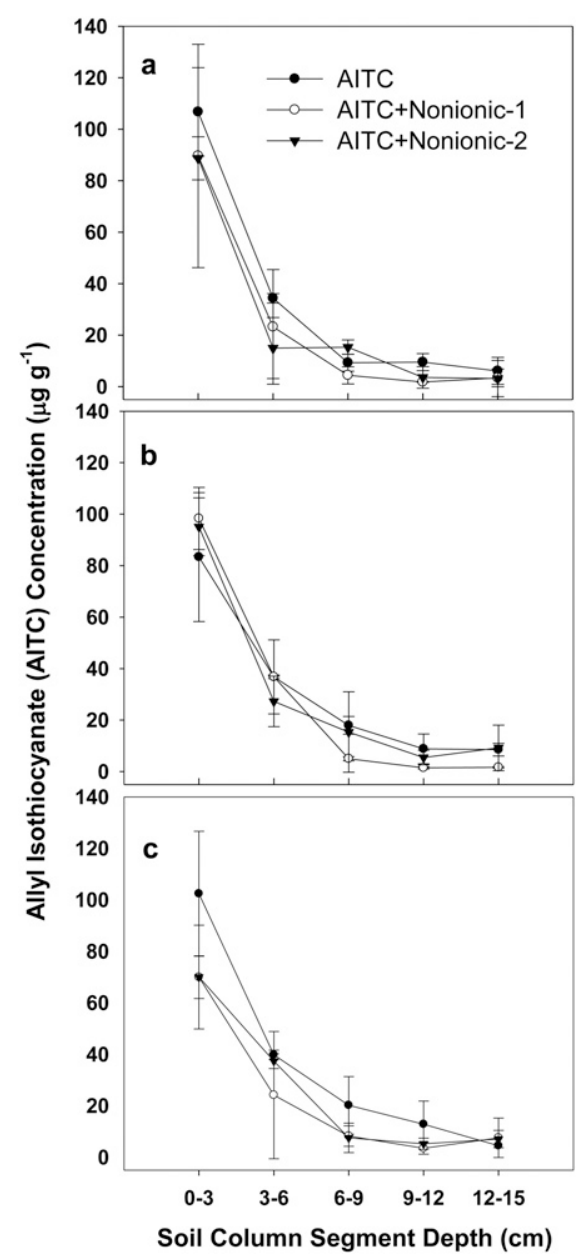

Fig. 4. Allyl isothiocyanate (AITC) concentration in soil column segments of Elder sandy loam soil (A), Chualar loam soil (B), and Blanco clay loam soil $(\mathbf{C})$. Each column was divided into five equal segments. Each soil segment is $3 \mathrm{~cm}$ thick.

tested. The addition of nonionic-2 to AITC had minimal effects on mobility, whereas the addition of nonionic-1 increased AITC mobility across all soil classes (Fig. 2). The difference in mobility was attributed to the infiltration rate and the time required to collect the leaching fractions. Elder sandy loam soil fraction collection time was the shortest, followed by Chualar loam; the Blanco clay loam series had the longest collection time (Fig. 3).

The addition of anionic-1 improved AITC mobility, with differences among soils. For the Chualar loam series, the addition of nonionic-1 resulted in an average AITC concentration of $47 \mu \mathrm{g} \cdot \mathrm{mL}^{-1}$ across all collected fractions; however, in Elder sandy loam and Blanco clay loam soils, the average concentrations were 29 and $31 \mu \mathrm{g} \cdot \mathrm{mL}^{-1}$ across all fractions, respectively. Furthermore, there were differences between soils tested during the amount of time required to reach the maximum AITC concentration. In Chualar loam, the maximum concentration was reached between leachate fractions three and four, whereas the maximum concentrations were reached at leachate fractions eight and nine and at leachate fractions 17 and 18

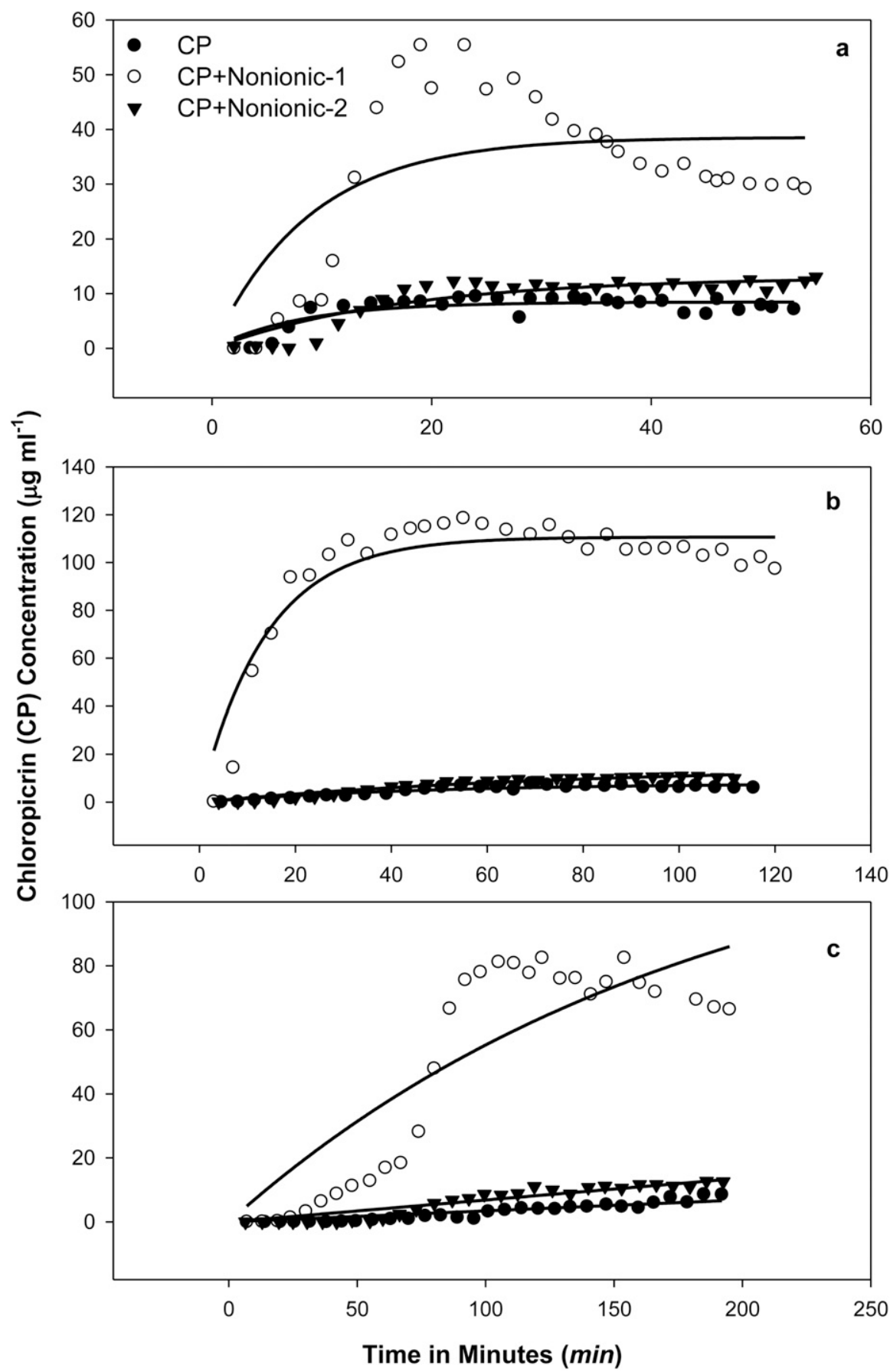

Fig. 5. First-order reaction rate model fitting for chloropicrin (CP) in leachate when applied alone, with nonionic-1, and with nonionic-2 in Elder sandy loam soil (A), Chualar loam soil (B), and Blanco clay loam soil (C). SE bars are not shown for clarity of the graph.

for the Elder sandy loam soil and Blanco clay loam soil, respectively (data not shown).

The AITC maximum concentration in the leachate fraction was highest when nonionic1 surfactant was added. The elder sandy loam series had a maximum AITC concentration of $9 \mu \mathrm{g} \cdot \mathrm{mL}^{-1}$ for AITC alone compared with 42 and $20 \mu \mathrm{g} \cdot \mathrm{mL}^{-1}$ when nonionic- 1 and nonionic-2 were added, respectively. The maximum AITC concentrations in Chualar loam leachates were 11,51 , and $13 \mu \mathrm{g} \cdot \mathrm{mL}^{-1}$ for AITC applied alone, AITC plus nonionic1 surfactant, and AITC plus nonionic-2 surfactant, respectively. A similar pattern was observed for the Blanco clay loam series, with maximum AITC concentrations of 17 , 50 , and $23 \mu \mathrm{g} \cdot \mathrm{mL}^{-1}$ for AITC alone, AITC with nonionic-1 surfactant, and AITC with nonionic-2 surfactant, respectively. Total AITC recovered in the collected leachate was lowest for AITC alone and highest for nonionic-1 surfactant treatment across all soils (Table 3 ). The reaction model constant (K) was higher when AITC was mixed with nonionic-1 (Table 2); $\mathrm{K}$ represents the change in concentration of AITC over time (Fig. 1). In addition, the half-life values were lowest with nonionic-1, except for the Blanco 


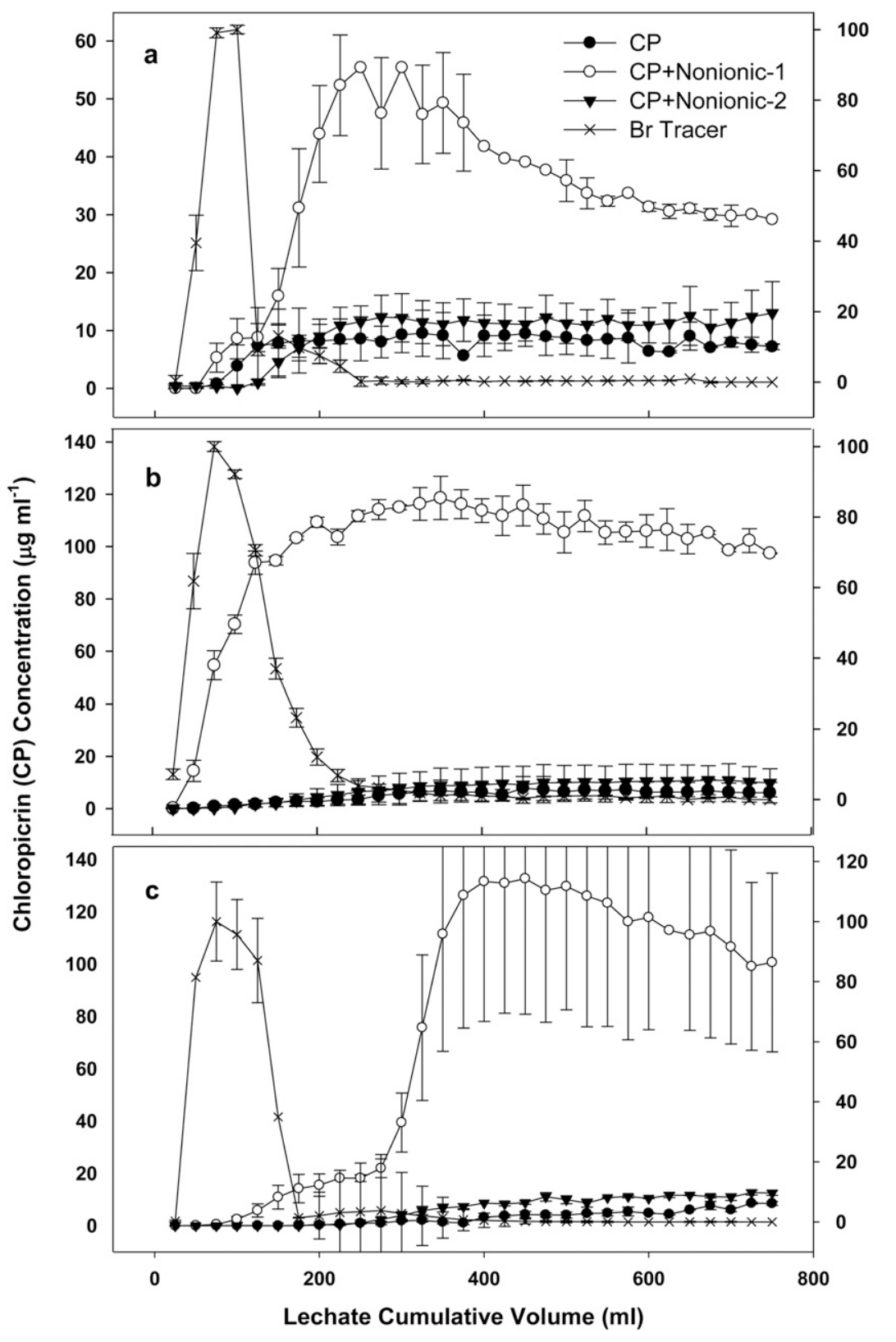

Fig. 6. Chloropicrin (CP) and bromide tracer concentrations in soil leachate collected over time from Elder sandy loam soil (A), Chualar loam soil (B), and Blanco clay loam soil (C). CP was applied alone or in combination with nonionic-1 or nonionic- 2 .

clay loam soil when AITC was applied with nonionic-2. This difference could be a result of the higher organic matter and the specific interaction between nonionic-2 and organic matter. Szajdak et al. (2014) showed that higher $\mathrm{K}$ values are associated with higher organic matter. The effect of nonionic- 1 on $\mathrm{K}$ values could be attributed to the fumigant staying longer in solution and not adsorbing on soil particles, thereby possibly increasing fumigant residence time in soil.

The soil AITC analysis showed limited AITC movement from the application spot regardless of the surfactant type used (Fig. 4). This response suggested that the risk of AITC leaching from the soil is minimal. In this study, $750 \mathrm{~mL}$ of water was used to leach each soil column. Under field conditions, when AITC was applied through the drip irrigation system, the drip system required $78 \mathrm{~h}$ to deliver the same volume of water that was used in our study. The typical drip irrigation system for strawberries usually consists of two drip lines per bed with an output capacity of $1.9 \mathrm{~L} \cdot \mathrm{min}^{-1}$ for $30 \mathrm{~m}$ of drip tape.

$C P$ mobility. Reaction model results indicated that $C P$ had a different response than AITC (Fig. 5). In Elder sandy loam soil, the K values for $\mathrm{CP}$ alone and $\mathrm{CP}$ with nonionic-1 were similar (Table 2); however, $\mathrm{CP}$ and nonionic-2 resulted in lower $\mathrm{K}$ values. The data suggest that nonionic-1 allows the $\mathrm{CP}$ to stay in solution longer, resulting in higher concentrations in the leachate when compared with $\mathrm{CP}$ applied alone without any surfactants. In Chualar loam soil, CP applied with nonionic-1 had the highest $\mathrm{K}$ value (Table 2) and the lowest half-life time, suggesting that with $\mathrm{CP}$, the surfactant could affect the adsorption of the chemical due to soil textural differences (Szajdak et al., 2014). CP applied in Blanco clay loam soil with nonionic-1 resulted in the highest $\mathrm{K}$ value (Table 2). The soil texture had the strongest influence on CP movement through soil; however, when nonionic-1 was used, that influence was minimized and the $\mathrm{CP}$ concentration was increased in the leachate.

Without surfactants, the mobility of $\mathrm{CP}$ was similar across all soils. The addition of the nonionic-2 surfactant to $\mathrm{CP}$ did not enhance soil mobility; however, nonionic-1 surfactant significantly enhanced CP soil mobility (Fig. 6). For the Elder sandy loam, when CP was applied without any surfactant, the average concentration across all leachate fractions collected was $5 \mu \mathrm{g} \cdot \mathrm{mL}^{-1}$, whereas average concentrations of 7 and $3 \mu \mathrm{g} \cdot \mathrm{mL}^{-1}$ were detected for the Chualar loam and Blanco clay loam, respectively. When nonionic-1 surfactant was added, the average $\mathrm{CP}$ concentrations across all fractions were 32,98 , and $48 \mu \mathrm{g} \cdot \mathrm{mL}^{-1}$ for the Elder sandy loam, Chualar loam, and Blanco clay loam series, respectively.

The effect of soil texture on CP was more related to the water infiltration rate (Fig. 3), and the difference involved the time required to collect the leachate as related to the infiltration rate. The time to reach the maximum $\mathrm{CP}$ concentration was different depending on soil texture. In Chualar loam soil, the maximum concentration was between leachate fractions 9 and 10 compared with between leachate fractions 8 and 9 for the Elder sandy loam soil and between leachate fractions 15 and 16 for the Blanco clay loam soil. The total $\mathrm{CP}$ recovered in all collected leachates was lowest when it was applied without surfactants, and it was highest when it was applied with nonionic-1 surfactant across different soils (Table 3).

The soil CP concentration was the highest in the top $3 \mathrm{~cm}$ closest to the application spot, indicating that $\mathrm{CP}$ did not move far from the application site regardless of the surfactant type (Fig. 7). This response suggested that the risk of leaching CP from the soil is minimal, similar to the case of AITC.

Most research of fumigant alternatives to $\mathrm{MeBr}$ suggested that no single alternative will replace $\mathrm{MeBr}$; therefore, an integrated pest management program including prevention and chemical and nonchemical tactics needs to be implemented to obtain acceptable pest control (Downing 2016; UCIPM 2019). $\mathrm{CP}$ in combination with $1,3-\mathrm{D}$ is the fumigant mixture that has been most widely adapted for a multitude of products (Gao et al., 2012; Klose et al., 2008). However, AITC is expected to be used in combination with $\mathrm{CP}$; therefore, increased soil mobility of fumigant mixtures in the presence of surfactant is important to improve pest control efficacy. Increases in CP and AITC soil mobility due to the addition of nonionic-1 surfactant were, on average, 5-times and 13-times more, respectively, than that of CP and AITC applied alone across all soils (Table 3 ). 


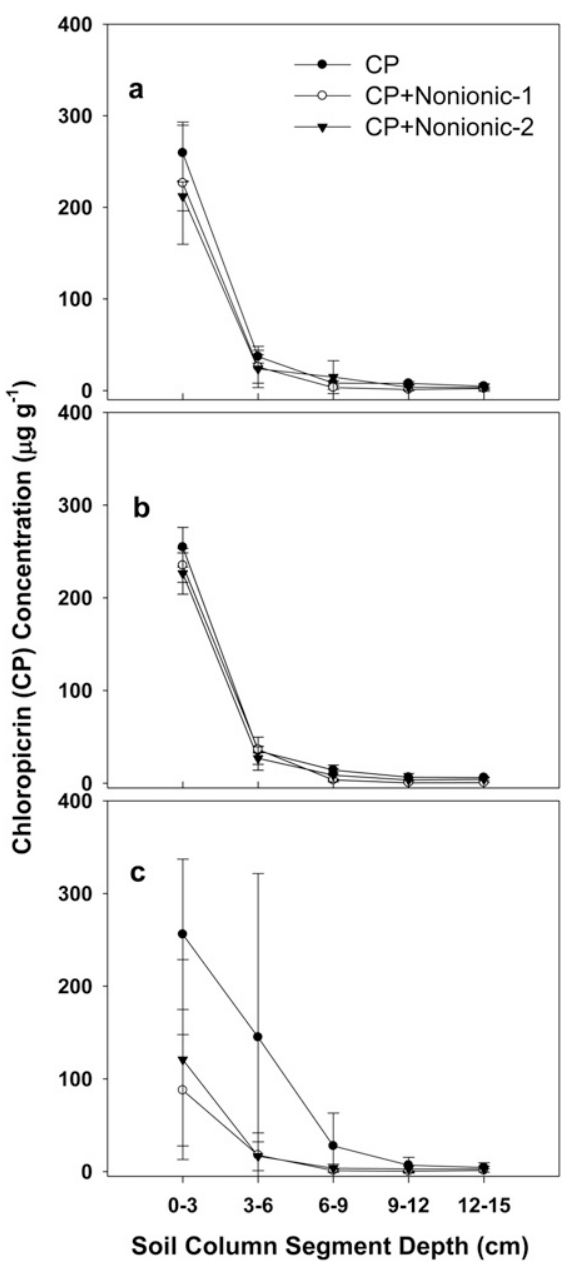

Fig. 7. Chloropicrin (CP) concentration in soil column segments of Elder sandy loam soil (A), Chualar loam soil (B), and Blanco clay loam soil (C). Each column was divided into five equal segments. Each soil segment is $3 \mathrm{~cm}$ thick.

AITC soil mobility and CP soil mobility were greater when applied with nonionic-1 surfactant compared with nonionic-2 surfactant, indicating that the type of surfactant used is an important factor when determining the magnitude of efficacy enhancement, as suggested previously (Santos et al., 2013). Surfactants are a group of amphiphilic chemicals that contain hydrophilic and hydrophobic parts in the molecular structure, thereby enhancing the water solubility of hydrophobic chemicals (Mao et al., 2015). Adsorption behavior of the surfactants on soil and the solubilizing ability of surfactants with the target chemical are important considerations when selecting appropriate surfactants; both factors are governed by the molecular structure of the surfactant. For example, adsorption of the surfactant on soil particles is increased by increasing the alkyl chain length for C5-C15 (Sanchez-Camazano et al., 1995). The differences between the soil mobility of fumigant when applied with nonionic-2 and nonionic-1 are most likely due to the molecular structure of the surfactant with nonionic-2 having a longer alkyl chain.
Nonionic-1 surfactant enhanced the soil mobility of AITC and CP across different soil types; however, the magnitude of enhancement was not equal across soil types. Data suggested that soil organic matter could affect the adsorption behavior of the nonionic surfactant by altering the bonding properties of the soil-water system; this was demonstrated by the results presented in Table 2 for the first-order reaction rate constant. Soil colloids are negatively charged and can bind with cationic and anionic surfactants by ion exchange and ion matching (Paria, 2008), thereby decreasing the surface tension between soil and water and allowing chemical movement through the soil, which could explain the results obtained during this study. It is also possible that nonionic-1 surfactant enhances water influx into the soil, which reduces the residence time and the potential for chemicals to adsorb on the soil.

To increase the efficacy of isothiocyanate generators, most research suggested that residence time and concentration need to be increased (Nelson et al., 2013). Methods of mechanical manipulation of fumigant placement in the soil, including using multiple drip lines, increasing water volume, increasing the depth of application, and using total impermeable film to prevent the fumigant from escaping into the atmosphere (Gilreath et al., 2008; Jacoby, 2016; Papiernik et al., 2004; Rodriguez, 2002; Yates et al., 2002), have been reported in the literature. Although some of these techniques showed some potential for improving the efficacy of AITC and $\mathrm{CP}$, the efficacy is still inconsistent because AITC and CP are not soluble in water (Isagro, 2016; Saeed et al., 1997); therefore, we assumed that, when applied to the soil, CP and AITC are strongly adsorbed on the soil particles. For greater distribution and increased residence time, CP and AITC need to be desorbed from the soil particles and distributed through the soil profile, as displayed by the higher $\mathrm{K}$ values when nonionic-1 is added.

Improvements in $\mathrm{CP}$ and $\mathrm{AITC}$ regarding pest control efficacy by mechanical placement manipulation reported in previous work (Gilreath et al., 2008; Jacoby, 2016; Papiernik et al., 2004; Rodriguez, 2002; Yates et al., 2002) may be dependent on adjusting the sorption/ desorption equilibrium in the soil. Our research suggested that when surfactants are present in the soil-water-chemical phase, the hydrophilic side bonds with water, the lipophilic side bonds with hydrophobic soil particles, and the hydrophobic particles of the chemical allow less adsorption of chemicals on soil particles, thereby allowing greater mobility of fumigants through the soil. This research showed that soil movement with the existing $\mathrm{MeBr}$ alternatives may be enhanced by using surfactants.

\section{Literature Cited}

Ahuja, I., J. Rohloff, and A.M. Bones. 2010. Defence mechanisms of Brassicaceae: Implications for plant-insect interactions and potential for integrated pest management. A review. Agron. Sustain. Dev. 30:311-348.
Ajwa, H.A. and H.J. Trout. 2006. Polyacrylamide and water quality effects on infiltration in sandy loam soils. Soil Sci. 70:643-650.

Ajwa, H.A. and T. Trout. 2004. Drip application of alternative fumigants to methyl bromide for strawberry production. HortScience 39:17071715.

Bangarwa, S.K., J.K. Norsworthy, E.E. Gbur, J. Zhang, and T. Habtom. 2011. Allyl isothiocyanate: A methyl bromide replacement in polyethylenemulched bell pepper. Weed Technol. 25:90-96.

Blake, G.R. and K.H. Hartge. 1986. Particle density, p. 377-382. In: A. Klute (ed.). Methods of soil analysis: Part 1. Physical and mineralogical methods. Soil Sci. Soc. Amer., Madison.

Butler, J.H. and J.M. Rodriguez. 1996. Methyl bromide in the atmosphere, p. 28-90. In: C.H. Bell, N. Price, and B. Chakrabarti (eds.). The methyl bromide issue. Wiley and Sons, New York.

Cuniff, P.E. 1995. Official methods of analysis: Agricultural chemicals, contaminants and drugs of AOAC international. Arlington: Association of Official Analytical Chemists. 1:1-18.

Devkota, P. and J.K. Norsworthy. 2014. Allyl isothiocyanate and metham sodium as methyl bromide alternatives for weed control in plasticulture tomato. Weed Technol. 28:377-384.

Downing, J. 2016. A crossroads for strawberries. Calif. Agr. 70:100.

EPA. 1997. Test methods for evaluating solid waste, physical/chemical methods, SW-846. 3rd ed. U.S. Government Printing Office, Washington, DC.

Everts, C.J., R.S. Kanwar, E.C. Alexander, and S.C. Alexander. 1989. Comparison of tracer motilities under laboratory and field conditions. Environmental Quality 18:491-498.

FDA. 2018. Synthetic flavoring substances and adjuvants. Dec. 2018. <https://www. ecfr.gov/cgi-bin/retrieveECFR?gp=1\&SID= 7b7b57d5468595d6b81a8a08c0e45c3f\&ty=HTM $\mathrm{L} \& \mathrm{~h}=\mathrm{L} \& \mathrm{mc}=$ true $\& \mathrm{r}=$ SECTION\&n $=\mathrm{se} 21.3 .172$ $1515>$

Gao, S., H. Ajwa, R. Qin, M. Stanghellini, and D. Sullivan. 2012. Emission and transport of 1, 3dichloropropene and chloropicrin in a large field tarped with VaporSafe TIF. Environ. Sci. Technol. 47:405-411.

Gilardi, G., A. Minuto, G. Minuto, A. Garibaldi, and M.L. Gullino. 2000. Activity of natural soil fumigants against soilborne pathogens. Colt. Prot. 29:71-76.

Gilreath, J.P., B.M. Santos, and T.N. Motis. 2008 Performance of methyl bromide alternatives in strawberry. HortTechnology 18:80-83.

Goodhue, R., M. Schweisguth, and K. Klonsky. 2016. Revised chloropicrin use requirements impact strawberry growers unequally. Calif. Agr. 70:116-123.

Guthman, J. and S. Brown. 2016. I will never eat another strawberry again: The biopolitics of consumer-citizenship in the fight against methyl iodide in California. Agr. Human Values 33:575-585.

Isagro. 2016. Dominus label. Dec. 2018. <https:// www.isagro.com/static/upload/10-/10-dominus. pdf $>$.

Jacoby, T.P. 2016. Improving the efficacy of methyl bromide alternatives for vegetable production in Florida. University of Florida, Gainesville, FL, Ph.D. dissertation.

Johnson, J.A., S.S. Walse, and J.S. Gerik. 2012. Status of alternatives for methyl bromide in the United States. Outlooks Pest Mgt. 23:5358.

Katagi, T. 2008. Surfactant effects on environmental behaviour of pesticides, p. 71-177. In: D.M. 
Whitacre (ed.). Reviews of environmental contamination and toxicology. Springer, New York.

Klose, S., H.A. Ajwa, G.T. Browne, K.V. Subbarao, F.N. Martin, S.A. Fennimore, and B.B. Westerdahl. 2008. Dose response of weed seeds, plant-parasitic nematodes, and pathogens to twelve rates of metam sodium in a California soil. Plant Dis. 92:1537-1546.

Kroetsch, D. and C. Wang. 2008. Particle size distribution, p. 713-726. In: M.R. Carter and E.G. Gregorich (eds.). Soil sampling and methods of analysis. CRC Press, Boca Raton.

López-Fernández, O., R. Rial-Otero, J. SimalGándara, and J. Boned. 2016. Dissipation kinetics of pre-plant pesticides in greenhousedevoted soils. Sci. Total Environ. 543:1-8.

Mao, X., R. Jiang, W. Xiao, and J. Yu. 2015. Use of surfactants for the remediation of contaminated soils: A review. J. Hazard. Mater. 285:419435.

Nelson, S.D., H.A. Ajwa, T. Trout, M. Stromberger, S.R. Yates, and S. Sharma. 2013. Water and methyl isothiocyanate distribution in soil after drip fumigation. J. Environ. Qual. 42:1555-1564.

Nelson, S.D., S.J. Locascio, L.H. Allen, D.W. Dickson, and D.J. Mitchell. 2002. Soil flooding and fumigant alternatives to methyl bromide in tomato and eggplant production. HortScience 37:1057-1060.
Noble, R.R., S.G. Harvey, and C.E. Sams. 2002. Toxicity of Indian mustard and allyl isothiocyanate to masked chafer beetle larvae. Plant Health Prog. Dec. 2018. <http://www. plantmanagementnetwork.org/pub/php/research/ chafer/noble.pdf $>$.

Papiernik, S.K., R.S. Dungan, W. Zheng, M. Guo, S.M. Lesch, and S.R. Yates. 2004. Effect of application variables on emissions and distribution of fumigants applied via subsurface drip irrigation. Environ. Sci. Technol. 38:54895496.

Paria, S. 2008. Surfactant-enhanced remediation of organic contaminated soil and water. Adv. Colloid Interface Sci. 138:24-58.

Rible, J.M. and J. Quick. 1960. Water soil plant tissue: Tentative methods of analysis for diagnostic purposes, Method S-19.0. University of California Agricultural Experiment Service, Davis.

Rodriguez-Kabana, R. 2002. Furfural-based biofumigant mixtures for control of phytopathogenic nematodes and weeds, p. 395. In: Proceedings of International Conference on Alternatives to Methyl Bromide. $<$ https://pdfs. semanticscholar.org/e50b/4b1 fe9195eaabfe4fd 8d3a75061f9edaa3a9.pdf\#page $=395>$.

Saeed, I.A.M., D.I. Rouse, J.M. Harkin, and K.P. Smith. 1997. Effects of soil water content and soil temperature on efficacy of metham-sodium against Verticillium dahliae. Plant Dis. 81:773776.

Sanchez-Camazano, M., M. Arienzo, M.J. SanchezMartin, and T. Crisanto. 1995. Effect of different surfactants on the mobility of selected non-ionic pesticides in soil. Chemosphere 31:3793-3801.

Santos, B.M., T.P. Jacoby, and N.S. Boyd. 2013. Improved nutesdge control on bed edges with metam potassium and soil surfactants, p. 22 23. In: The Florida Tomato Proceedings. University of Florida, Gainesville, Florida.

Szajdak, L.W., J. Lipiec, A. Siczek, A. Nosalewicz, and U. Majewska. 2014. Leaching kinetics of atrazine and inorganic chemicals in tilled and orchard soils. Intl. Agrophys. 28:231-237.

UCIPM. 2019. Strawberry pest management guidelines. University of California. Jan. 2019. $<$ https://www2.ipm.ucanr.edu/agriculture/ strawberry/>.

Wu, H., C.J. Wang, X.W. Bian, S.Y. Zeng, K.C. Lin, B. Wu, and X. Zhang. 2011. Nematicidal efficacy of isothiocyanates against root-knot nematode Meloidogyne javanica in cucumber. Crop Prot. 30:33-37.

Yates, S.R., J. Gan, S.K. Papiernik, R. Dungan, and D. Wang. 2002. Reducing fumigant emissions after soil application. Phytopathology 92:13441348 . 